\title{
Coupling Molecular Dynamics and Micromechanics for the Assessment of Friction and Damage Accumulation in Diamond-Like Carbon Thin Films under Lubricated Sliding Contacts
}

\author{
Timo J. Hakala, Kenneth Holmberg and Anssi Laukkanen *
}

check for updates

Citation: Hakala, T.J.; Holmberg, K.; Laukkanen, A. Coupling Molecular Dynamics and Micromechanics for the Assessment of Friction and Damage Accumulation in Diamond-Like Carbon Thin Films under Lubricated Sliding Contacts. Lubricants 2021, 9, 30. https:// doi.org/10.3390/lubricants9030030

Received: 15 February 2021

Accepted: 2 March 2021

Published: 5 March 2021

Publisher's Note: MDPI stays neutral with regard to jurisdictional claims in published maps and institutional affiliations.

Copyright: (c) 2021 by the authors. Licensee MDPI, Basel, Switzerland. This article is an open access article distributed under the terms and conditions of the Creative Commons Attribution (CC BY) license (https:/ / creativecommons.org/licenses/by/ $4.0 /)$.
VTT Integrated Computational Materials Engineering, VTT Technical Research Centre of Finland, Vuorimiehentie 3, VTT, 02044 Espoo, Finland; timo.j.hakala@vtt.fi (T.J.H.); kenneth.g.holmberg@gmail.com (K.H.)

* Correspondence: anssi.laukkanen@vtt.fi; Tel.: +358-4-7702369

\begin{abstract}
Diamond-like carbon (DLC) coatings have proven to be an excellent thin film solution for reducing friction of tribological systems as well as providing resistance to wear. These characteristics yield greater efficiency and longer lifetimes of tribological contacts with respect to surface solutions targeting for example automotive applications. However, the route from discovery to deployment of DLC films has taken its time and still the design of these solutions is largely done on a trialand-error basis. This results in challenges both in designing and optimizing DLC films for specific applications and limits the understanding, and subsequently exploitation, of many of the underlying physical mechanisms responsible for its favorable frictional response and high resistance to various types of wear. In current work multiscale modeling is utilized to study the friction and wear response of DLC thin films in dry and lubricated contacts. Atomic scale mechanisms responsible for friction due to interactions between the sliding surfaces and shearing of the amorphous carbon surface are utilized to establish frictional response for microstructure scale modeling of DLC to DLC surface contacts under dry and graphene lubricated conditions. Then at the coarser microstructural scale both structure of the multilayer, substrate and surface topography of the DLC coating are incorporated in studying of the behavior of the tribosystem. A fracture model is included to evaluate the nucleation and growth of wear damage leading either to loss of adhesion or failure of one of the film constituents. The results demonstrate the dependency of atomistic scale friction on film characteristics, particularly hybridization of bonding and tribochemistry. The microstructure scale modeling signifies the behavior of the film as a tribosystem, the various material properties and the surface topography interact to produce the explicitly modeled failure response. Ultimately, the work contributes towards establishing multiscale modeling capabilities to better understand and design novel DLC material solutions for various tribological applications.
\end{abstract}

Keywords: diamond-like carbon; multiscale modeling; thin films; molecular dynamics; finite element method; microstructure; friction; hard coatings; integrated computational materials engineering

\section{Introduction}

Diamond-like carbon (DLC) is the name commonly used for hard carbon coatings, which have similar mechanical, optical, electrical and chemical properties to natural diamond, but which do not have a dominant crystalline lattice structure. They are amorphous and consist of a mixture of $\mathrm{sp}^{2}$ and $\mathrm{sp}^{3}$ carbon structures with $\mathrm{sp}^{2}$-bonded graphite-like clusters embedded in an amorphous $\mathrm{sp}^{3}$-bonded carbon matrix [1,2]. Diamond-like carbon coatings have excellent tribological properties, very similar to the diamond coatings; they are chemically inert and have excellent biocompatibility. However, because of their amorphous structure they are less brittle than diamond coatings and due to their lower deposition temperature, down to room and even subzero temperatures, they can be deposited on a large variety of materials, including all kinds of metals and ceramics, with 
good adhesion. The coefficient of friction for DLC is generally in the range of $0.02-0.4$, in a vacuum or inert environment in the range of 0.001-0.02 [2,3].

The most important structural parameters for DLC coatings are the $\mathrm{sp}^{3} / \mathrm{sp}^{2}$ ratio and the hydrogen content. At higher temperatures a recrystallisation of the carbon structure to graphite takes place and this transition is depending on the $\mathrm{sp}^{3} / \mathrm{sp}^{2}$ ratio. Molecular dynamics (MD) simulations have shown that the three dimensional structure, not just the $\mathrm{sp}^{3} / \mathrm{sp}^{2}$ ratio, is important in determining the mechanical properties of the coatings. Particular orientations of $\mathrm{sp}^{2}$ ring-like structures create coatings with both high $\mathrm{sp}^{2}$ content and respective elastic constants. Coatings with graphite-like top layers parallel to the substrates have lower elastic constants than coatings with large amounts of $\mathrm{sp}^{3}$-hybridised carbon [4]. The layered structure of the hydrogen-free coatings results in a mechanical behavior that influences the friction to the load relationship. The atomic-scale structure of the coating at the interface has turned out to be of critical importance in determining the load at which tribochemical reactions and wear between the coating and the counterface are induced. The coatings that are highly hydrogenated provide enough hydrogen for all free dangling bonds to avoid the possibility that some strong covalent bonds are formed between the surfaces. Some unbonded free hydrogen can serve as a reservoir and replenish or replace those hydrogen atoms that may have been lost due to thermal heating and mechanical grinding during sliding [4].

The tribological friction and wear mechanisms in contacts with DLC coated surfaces may be very different depending on the geometrical and topographical scales investigated [5]. Some phenomena are best understood on the nanoscale while others may be better understood on micro- or macroscale. From an industrial application point of view it is important to manage to scale up and consolidate these mechanisms to macroscale conditions typically observed and measured in practical applications. It was already in the 90s, which speculated that the very low coefficient of friction of diamond-like carbon coatings in sliding contacts is due to graphitization and the formation of a thin graphitic layer on top of the hard coating [6]. Later a number of studies have pointed to the appearance of graphite in the wear tracks, which support the speculated theory. They have also shown another important contact mechanism that influences friction and wear-the formation of a carbon-rich transfer layer on the counter surface [7]. This transfer layer covers more or less completely the counter surface giving it a smooth load carrying platform ideal for low shear in combination with the graphitized top layer of the DLC coating. Transfer layers consisting of carbon, oxygen, chromium, aluminum and iron were observed. The result is that the friction occurs between two surfaces with amorphous carbon top layers, which have a structural chemistry quite different from the original DLC coating, but similar to that of crystalline graphite. In-situ transmission electron microscope (TEM) and electron energy loss spectra (EELS) analysis showing a mechanically-induced increase in $\mathrm{sp}^{2}$ bond content in the tribolayers formed on a-C:H nearly frictionless carbon coatings in sliding have also been carried out [8]. The study established a nanoscale sliding interface within the TEM and performed real-time imaging and spectroscopy of the moving contact and offered strong evidence that the formation of a graphitic layer is the frictional controlling mechanism. For higher hydrogen content in the coating, the surface is covered by hydrogen atoms, leading to weak van der Waals bonds between the sliding surfaces. For lower hydrogen content, on the other hand, there are not enough hydrogen atoms to shield the strong interactions between the free orbitals of carbon bonds. The very low coefficient of friction, often below 0.05 , when a steel slider slides over a hydrogenated DLC surface in dry air gradually increases with increasing humidity and reaches values in the range of $0.15-0.3$ at relative humidities close to $100 \%$ [6].

Understanding the lubrication of DLC coatings has been a challenge for years. The traditional lubricants and their additives do not perform with DLC coated surfaces in similar manner as they do with metallic surfaces, see for instance [1,9]. There has been many studies investigating how lubricant additives form the lubricating layers on the DLC surfaces but still there is a lot more to learn [10-12]. There are different ways to 
improve the lubrication of DLC surfaces. It has been studied, for example, how to modify the DLC coating with additives and utilize different types of lubricant additives [13-16]. Graphene has been found to be one efficient additive to reduce friction in DLC coated tribological systems [17]. To understand the lubricant behavior with different types of DLC surfaces in detail modeling is needed for systematically improving the understanding of the respective physical phenomena and causalities. Modeling of wear and friction of tribological contacts including DLC surfaces has gained more and more interest in the past few years and different kinds of models have been developed for wear prediction, e.g., statistical, dynamical, single asperity and simplified contact models [18-20]. Utilizing finite-element (FE) modeling to study the failure of DLC coatings has been demonstrated before in [3,5,21]. There are also papers published about lubrication modeling by FE [22] and wear analysis [23]. MD has been found a powerful tool to study what happens inside the tribocontact at the molecular level. Numerous papers have been published about $\mathrm{MD}$ and its use in wear prediction and tribofilm formation during contact between two surfaces [24,25]. Lan et al. [26] studied tribology between DLC and Si-DLC coatings by MD in unlubricated contacts. They found out that silicon content has little effect on friction and but it promotes transfer film bonding. Song et al. [27] have carried out MD to understand wear and formation of lubricating layer in water lubricated PTFE vs. copper contacts. Graphene lubrication effects were investigated by Bai et al. in [28] with profound effects to coefficient of friction, adhesion and roughness associated effects were investigated using MD by Ryan et al. in [29].

In this paper we demonstrate how to utilize MD and FE modeling in a simple unidirectional workflow to produce a coupling between surface friction behavior and fracture behavior of a coating system both in lubricated and non-lubricated DLC vs. DLC and DLC vs. diamond contacts. The work is a part of an effort to improve coupled multiscale modeling capabilities of DLC coatings in tribological problems, and as such, provide an improved basis for designing novel coating solutions with application performance associated requirements in mind. To that effect, we set up both MD and FE models and establish a connection via the MD computed coefficient of friction for different non-lubricated and lubricated DLC film containing contacts. The methodology is demonstrated in predicting a coating fracture load at the scale of the coating system microstructure utilizing the information transfer between the two modeling scales. As this workflow enables one to couple atomistic features to microstructural characteristics, it enables one to investigate the causal relations between, for example, the DLC structure and composition, lubricant, coating substrate and bond layer, surface roughness and loading conditions to coating system performance, providing one with the ability to design and tailor tribological solutions towards specific application performance requirements.

\section{Modeling Concept, Materials and Methods}

The current work is part of a greater effort to establishing multiscale modeling capabilities for DLC coated surfaces, as presented in Figure 1, where the modeling workflow being developed is presented in more detail. Presently, we incorporate aspects, which involve MD modeling, scale bridging via MD calculated values for the coefficient of friction under different tribochemical conditions for different DLC films, and the assessment of the DLC-bond layer-substrate system performance under mechanical contact utilizing micromechanical modeling. The methodology is being developed to further incorporate effects arising from, for example, operational conditions such as those arising from elevated temperatures. Another detail of further interest not being explored in detail in current work is the level and type of coupling between the atomistic and microstructural scales, where the degree of concurrency enables more information arising from the MD modeling to be transferred to the micromechanical modeling. The model in the atomistic scale takes into account for example temperature, tribochemical reactions and atomistic structure of DLC coating while the microstructural scale FE model includes parameters such as surface topography and loading conditions. In this work, we utilize simply MD computed 
coefficients of friction to inform the microscale of the atomistic scale behavior both for lubricated and non-lubricated contacts.

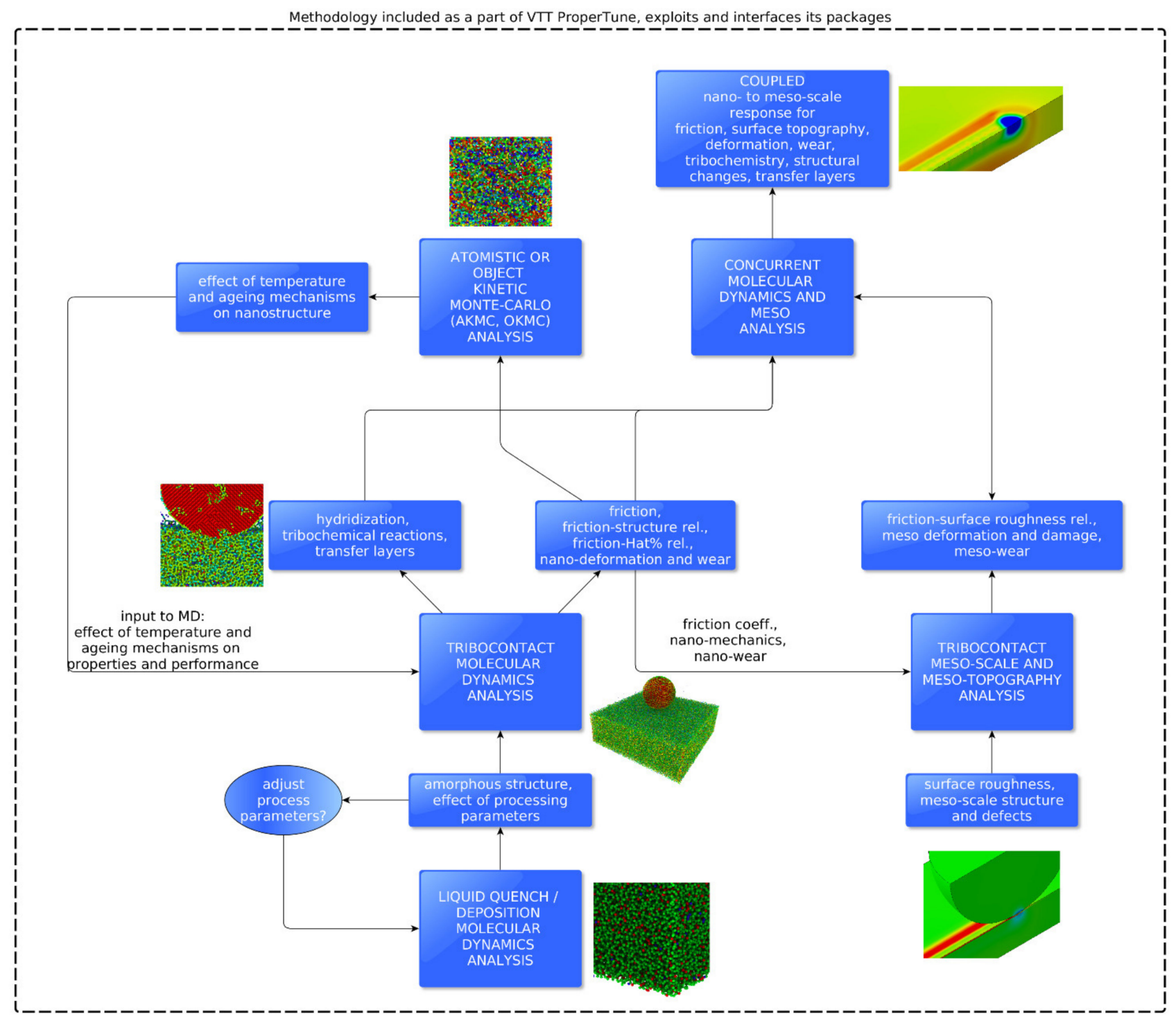

Figure 1. Multiscale modeling solution for diamond-like carbon (DLC) thin films.

\subsection{Materials}

For this work several different DLC film systems were studied. This involves a-C (amorphous carbon), a-C:H (hydrogenated amorphous carbon) and ta-C (tetrahedral amorphous carbon) films and also analysis cases were performed such that sheets of graphene act as a lubricant in the MD simulations. Similar coating systems have been studied by the authors earlier experimentally in $[3,21,30,31]$ and the experimental information for model parameterization, surface roughnesses, bond layers, substrate properties, etc., are presented in the respective articles in detail. Presently, some of the specifics of the associated work are briefly summarized.

In [3] DLC coatings with three different surface topographies were prepared, their topography and surface roughness were adjusted by way of controlling the quality of the substrate surface. Roughness Ra values were $0.004 \mathrm{~mm}, 0.012 \mathrm{~mm}$ and $0.1 \mathrm{~mm}$. Coating thickness was $1.7 \mathrm{~mm}$ (DLC $1.1 \mathrm{~mm}$, gradient layer $\mathrm{CrC}_{\mathrm{x}} 0.4 \mathrm{~mm}$ and buffer layer $\mathrm{Cr}$ $0.2 \mathrm{~mm}$ ). The substrate is a bearing steel. Coating and its properties are presented in detail 
by Holmberg et al. [3]. In addition to a-C:H coatings a-C and ta-C coatings are investigated in the following modeling activity.

\subsection{Molecular Dynamics}

Molecular dynamics (MD) analysis can take a direct stance on the mechanisms of friction, material damage and wear arising from the nanoscale. MD analyses have been carried out for DLC and carbon materials in general using various force fields, in current work the adaptive intermolecular reactive empirical bond order potential (AIREBO) potential is utilized [32], the potential framework is utilized for DLC, for example, in [33-35], and can be considered a general and computationally effective approach to assess interactions and chemical reactivity of various hydrocarbon systems. The AIREBO potential as a reactive potential incorporates the transition from van der Waals to covalent bonding, being as such well suited for current work. The MD code being utilized is LAMMPS [36].

The amorphous DLC structures are derived using a liquid quench (LQ) method, where a randomized ordered cubic lattice of $\mathrm{C}$ and $\mathrm{H}$ in the respective fractions of a given density is allowed to spontaneously melt. After melting and reaching temperatures of approximately $8000 \mathrm{~K}$ the system is thermostatted using velocity rescaling and stabilized. After a stabilization period cooling to $300 \mathrm{~K}$ is conducted using several temperature gradients and again velocity rescaling, followed by a stabilization period of the final structure. What results is an amorphous $\mathrm{C}-\mathrm{H}$ structure to be utilized as a starting structure in further analyses. Further details of the utilized liquid quench method are presented, for example, in [37].

One of the main goals in MD studies of DLC is identification of the mechanisms responsible for its performance with respect to friction, i.e., the reasoning underlying the low coefficients of friction and on the other hand limitations in its range of application. MD modeling was performed both for indentation and scratch testing, the latter utilized to extract a frictional response for micromechanical tribological modeling. Thus, the models implement a scratch test with increasing loading, the range deduced such that different types of surface interactions are produced (under displacement control). The microcanonical ensemble (NVE) was utilized for time integration, and velocity rescaling was utilized for temperature control. Different sized MD models were generated using the liquid quench (LQ) approach, from test models in the size range of hundreds of $\AA$ all the way to larger models representable of nanoindentation conditions with dimensions in the range of tens of nanometers.

\subsection{Finite-Element Modeling}

Micromechanical and macroscale modeling is commonly carried out using the finite element (FE) method, since it provides information already at the scale of the material system microstructure and as such findings typically yield a direct link to component performance. The best all around method for determination of mechanical performance of coatings is the scratch test, and as such, current FE work focuses in assessing deformation and failure behavior of DLC coatings undergoing a simulated scratch test. The utilized FE methodology for assessing the DLC coating system under contacts is a further development of work carried out by the authors in [21].

The approach is micromechanical, and as such, the DLC film, bond layer and underlying substrate are modeled in a full field manner. This involves describing the surface topography by way of imaging based modeling, in the current case anisotrotropic fractal description adopted from [38] was utilized. The mechanical behavior was modeled using crystal plasticity modeling for the substrate material, the material model was that presented by the authors in more detail in [39]. The fracture of the coating and damage accumulation is directly included in current work, the failure model is a so called "WST" model, which is a failure model particularly suited for brittle materials and has been developed by the authors in [40]. The tribocontact is solved in finite sliding and finite strain conditions using a Coulombian friction model and implicit time integration. The derivation 
of numerical models with surface topography and discretization of the polycrystalline and multilayer microstructures involves various tools and stages, these are described in more detail in $[38,41,42]$. The models were run in displacement control adopting the experimental conditions of [3], the sliding speed was $0.01 \mathrm{~m} / \mathrm{s}$ and loading was increased in a stepwise manner until failure.

\section{Numerical Models}

\subsection{Molecular Dynamics Models}

MD was utilized to create different DLC surfaces and structures. Those models were created with the LQ method as described earlier, Figure 2 presents the simulation of such a structure formation for the a-C:H coating containing 15 percent of hydrogen, the sequence from spontaneous melting of the initially unstable lattice to its cooling with velocity rescaling and stabilization to yield a specific DLC structure. Figure 3 shows snapshots of the specific stages of the a-C:H structure at different instances of time during the liquid quenching process. The coloring indicates differences in sp coordination: red is $\mathrm{sp} 1$, green $\mathrm{sp}^{2}$ and blue corresponds to $\mathrm{sp}^{3}$ coordination. Utilizing the LQ methodology various DLC structures were created, the ones of primary interest in current work and investigated in detail with respect to their differing tribochemical and sliding behavior are collated to Figure 4.

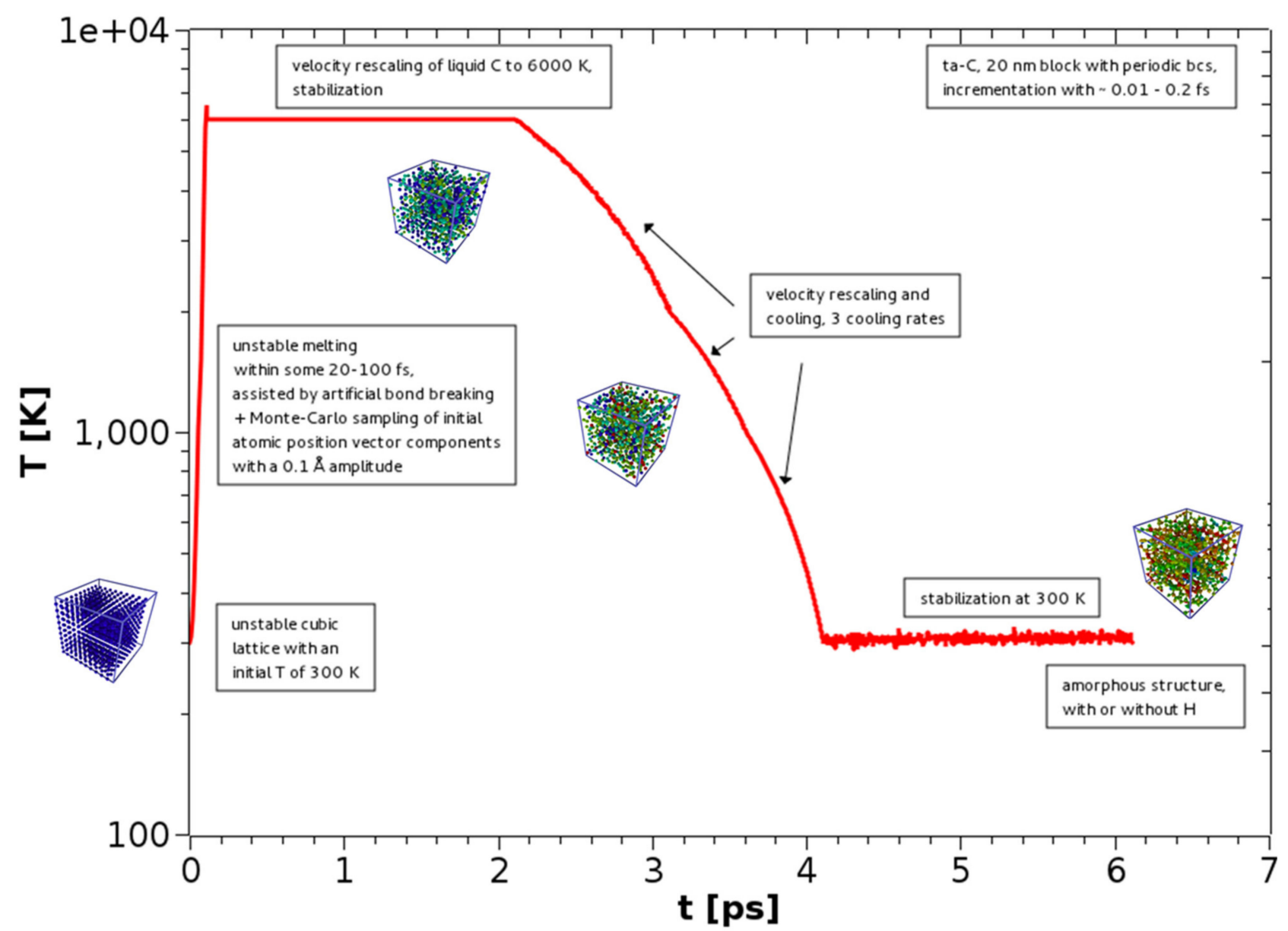

Figure 2. Plot of liquid quench time-temperature in preparing an amorphous a-C:H DLC structure. 

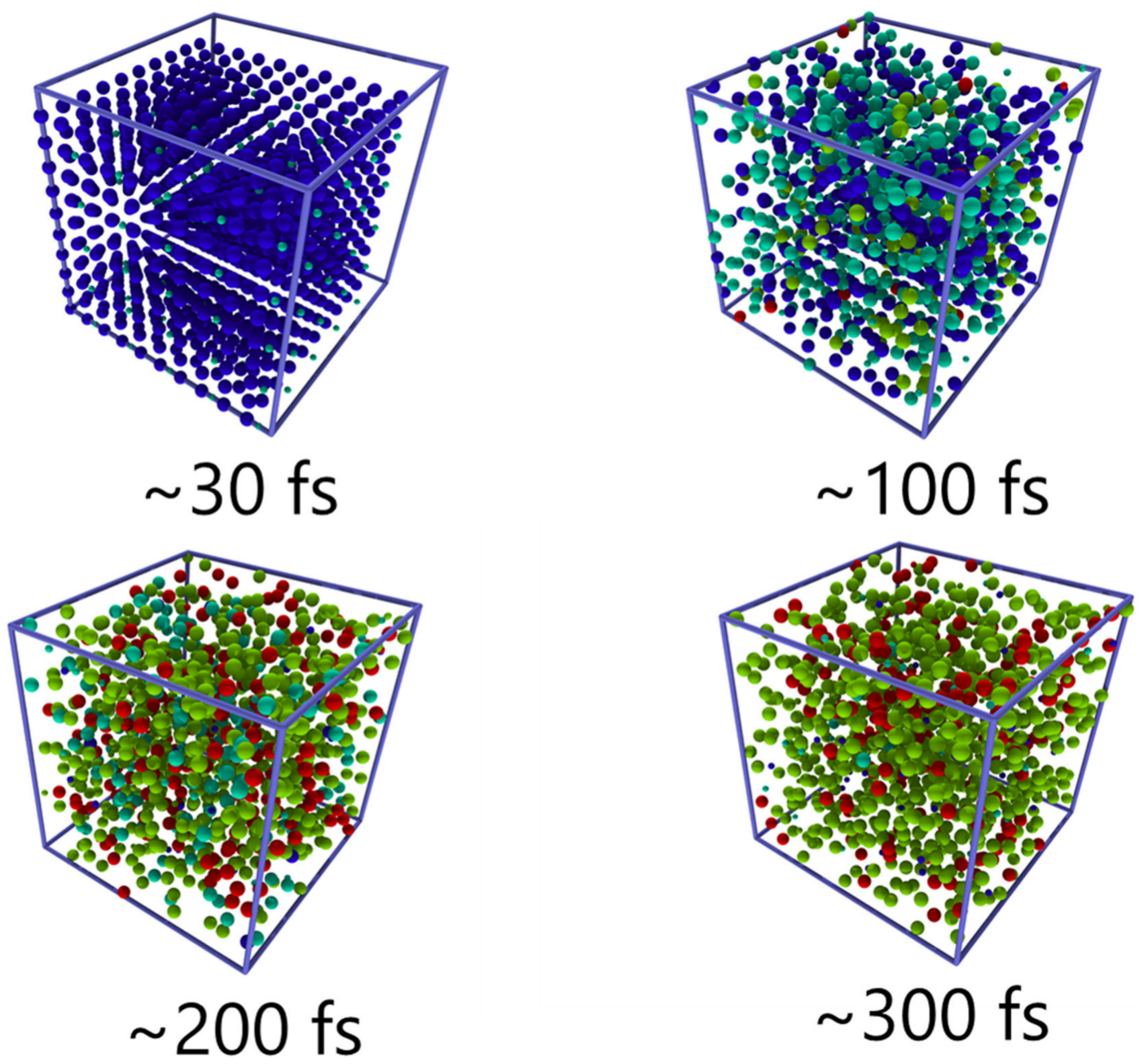

Figure 3. Sequence of liquid quenching of a a-C:H block with 15 at $\%$ of hydrogen.

a)

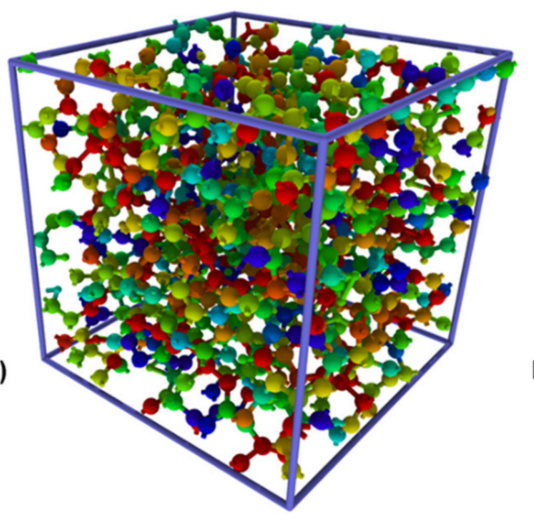

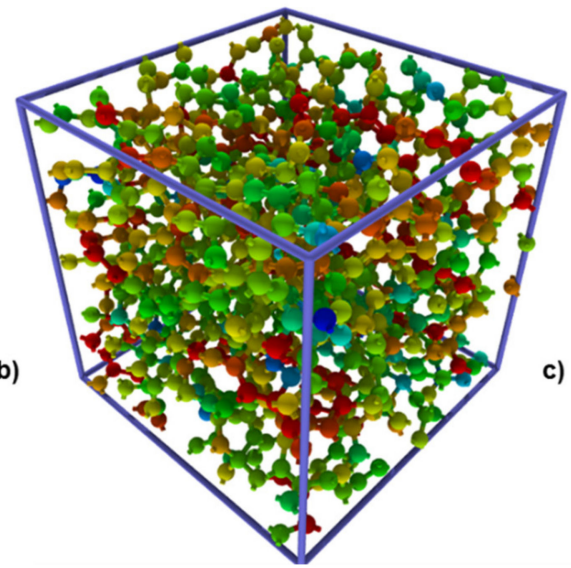

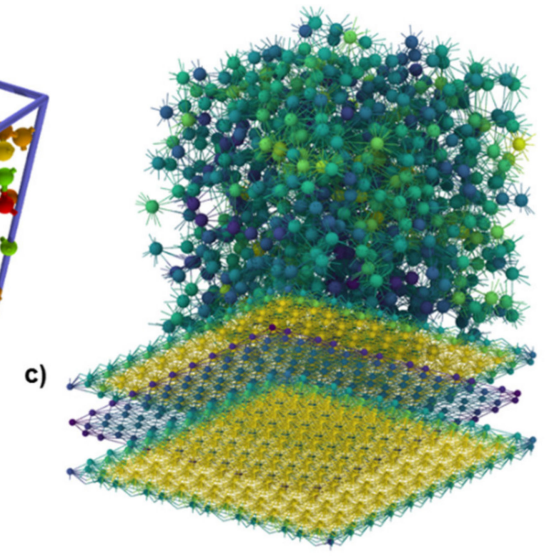

Figure 4. The various studied DLC structures: (a) a-C:H DLC structure with 15 at $\%$ hydrogen, (b) Ta-C. DLC structure and (c) a-C:H structure and multilayer graphene lubricant.

\subsection{Finite-Element Contact Model}

The FE model layout utilized for micromechanical modeling of the tribocontact is presented in Figure 5. With respect to characteristics of the system all the critical microstructural features are included. These include the DLC film treated as isotropic, the 
graded bond layer adopted from [21] (which is modeled as a multilayer to account for the respective mechanical property gradient) and the substrate microstructure modeled as a polycrystalline with crystal plasticity, and as such, the resulting anisotropic plasticity effects are fully accounted for. While MD models did not take into account the surface topography at the scale of the microstructure the FE contact models did include it explicitly, i.e., all the three principal phase domains include it based on measurement data given in [3], which was fitted to an anisotropic fractal description of surface roughness. The counterface to the topographical surface is smooth, i.e., the system corresponds to a DLC vs. DLC or largely also to diamond vs. diamond contact condition (the counterface is analytically rigid, thus corresponds best to a diamond tip or surface). The FE model size as depicted in Figure 5 was approximately 25 by $25 \mathrm{~mm}$.

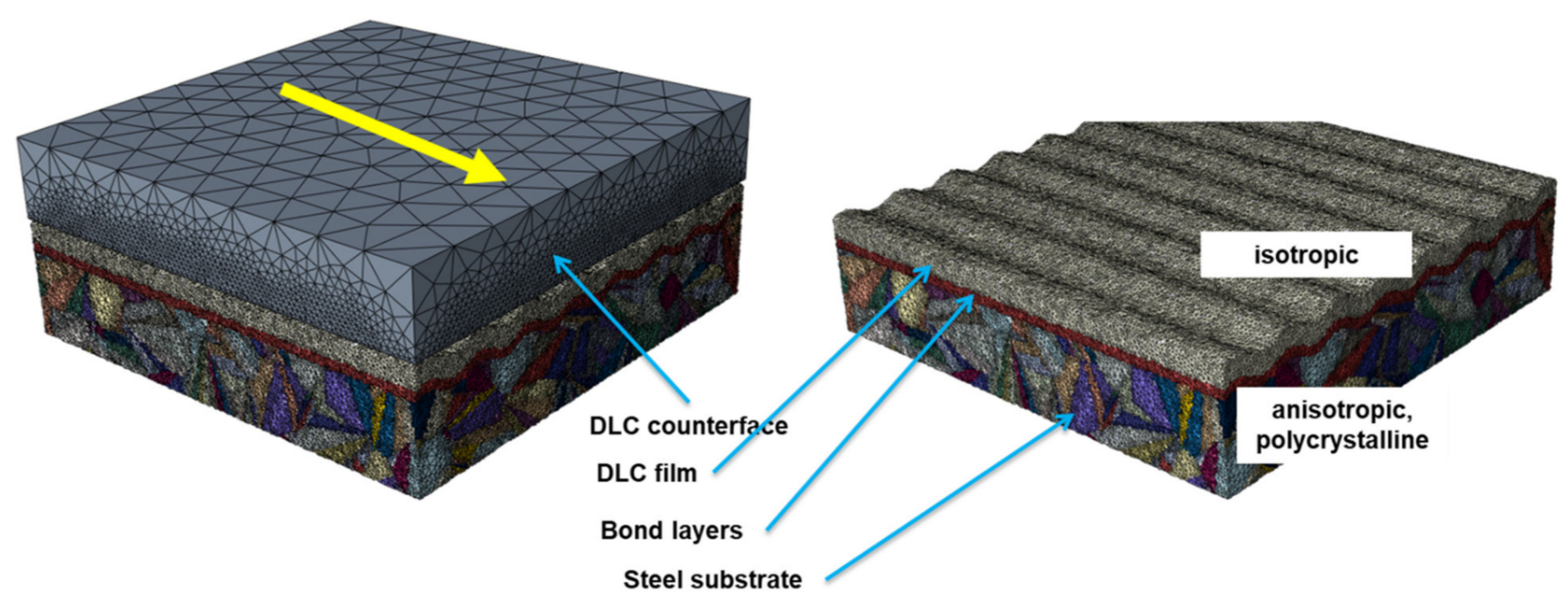

Figure 5. Finite element mesh of a smooth-on-rough contact of the DLC thin film, bond layer and a substrate microstructure and a smooth counterface.

The model "thickness" direction was selected simply to be large enough to ensure the contact simulation results are independent of the boundary conditions. The FE model parameters are presented in Table 1 , the parameters were adapted from earlier experimental work of the authors presented in detail in $[3,21]$ with respect to the coatings characteristics and in $[40,43]$ especially with respect to the failure model. 
Table 1. Collated Micromechanical Finite-Element (FE) Model Parameters.

\begin{tabular}{ccc}
\hline DLC Coated Surface & Symbol (Unit) & \\
\hline Total coating thickness & $\mathrm{h}(\mu \mathrm{m})$ & $1.76 \pm 0.04$ \\
\hline $\begin{array}{c}\text { Surface hardness (nano) } \\
\text { (nano) }\end{array}$ & $\mathrm{H}(\mathrm{GPa})$ & $205 \pm 10$ \\
\hline $\begin{array}{c}\text { Surface elastic modulus } \\
\text { Surface Poisson's ratio }\end{array}$ & $\mathrm{E}(\mathrm{GPa})$ & 0.202 \\
\hline Surface roughness & $\mathrm{v}(-)$ & 0.01 \\
\hline $\begin{array}{c}\text { Surface roughness VOT } \\
\text { Steel substrate }\end{array}$ & $\mathrm{R}_{\mathrm{a}}(\mu \mathrm{m})$ & $2.55 / 2.66 / 2.78 / 0.58$ \\
\hline Mean & \\
\hline Surface elastic modulus & $\mathrm{FS}_{0} / \mathrm{FS}{ }_{45} /$ \\
& $\mathrm{FS} / \mathrm{StrS}$ & $205 \pm 10$ \\
\hline Surface Poisson's ratio & $\mathrm{E}(\mathrm{GPa})$ & 0.3 \\
\hline Surface roughness & $\mathrm{v}(-)$ & 0.01 \\
\hline Yield strength $(0.2 \%$ strain) & $\mathrm{R}_{\mathrm{a}}(\mu \mathrm{m})$ & 2100 \\
\hline Tensile strength & $\mathrm{MPa}$ & 2200 \\
\hline Tangent modulus & $\mathrm{MPa}$ & 22.0 \\
\hline
\end{tabular}

\section{Results}

\subsection{Molecular Dynamics of Different DLC Coatings}

MD models used for indentation and scratch test simulations and overall results are presented in Figure 6. The initial diamond tip (sphere) vs. nominally flat surface is shown, and a sequence of how surface coordination evolves during indentation and the large scale model layout (cut diagonally) used for scratch test simulations. Of particular interest with respect to the current work is the triboreactivity of the different DLC surfaces when subjected to a sliding contact. This especially with respect to conditions, which lead to superlubricity-like conditions, surface shearing and formation of the respective tribolayers and triboreactivity leading to covalent bond formation and subsequently to elevated values of coefficient of friction. The outcome from MD simulations is then the input to FE modeling, which focuses on quantifying the significance of different surface frictional behaviors with respect to coating system performance and integrity. Molecular dynamics shows at the atomic level what kind of phenomena on the surfaces at the atomistic scale are taking place in contact.

Selected on the basis of the extremes of a frictional response, with respect to high values of friction and most active tribochemistry resulting from the formation of covalent bonds, Figure 7 shows how bonding is arranged in a ta-C film under contact with the diamond tip. The figures relate to different stages of progressively increasing loading during a scratch test, the principles of setting up the scratch testing conditions motivated by respective experiments performed in [3]. Figure 7a relates to the earlier stages of scratching the ta-C surface, in this case without hydrogen and the surface has neither been terminated by hydrogen bonds. For ta-C surfaces, as presented in more detail in the following, this stage of limited surface interaction is only a brief instant of the progressive loading sequence. Stronger interactions, which however do lead to limited surface reorientation and signs of shear associated reorientation and "graphitization" immediately underneath the diamond tip are seen in Figure $7 \mathrm{~b}$. 
a)

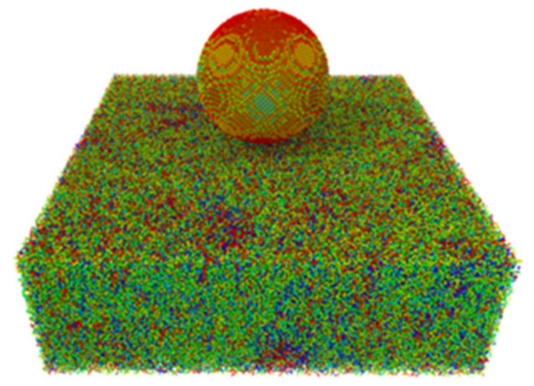

b)

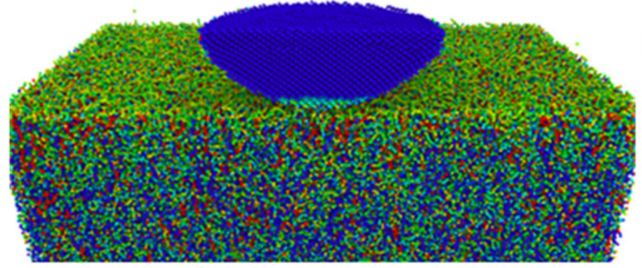

d)

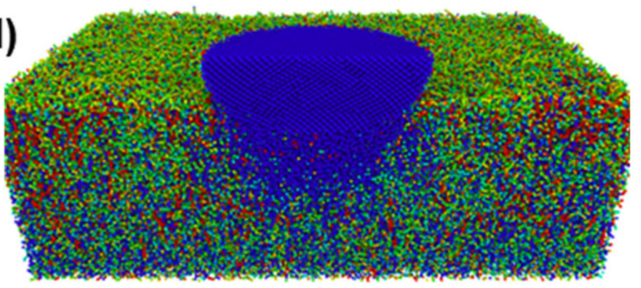

c)
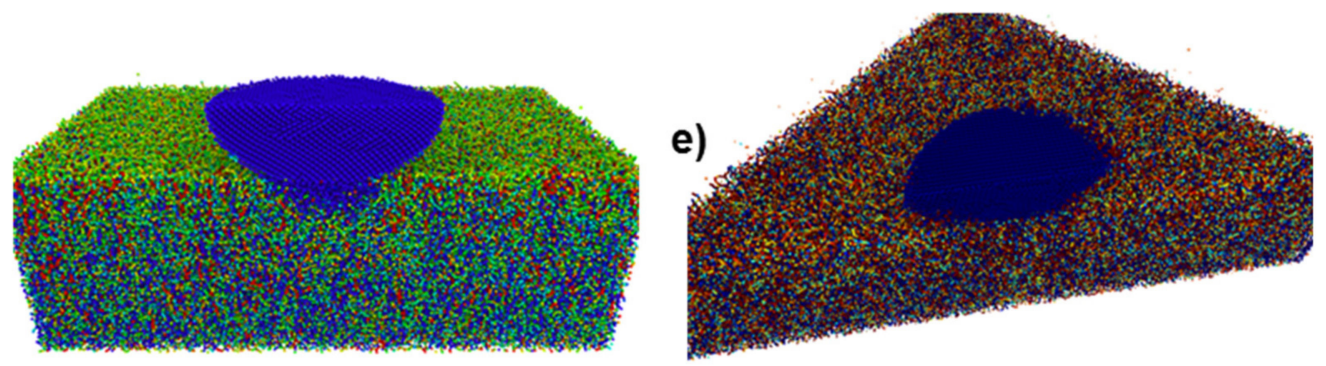

Figure 6. Scratch testing of a-C:H (25 atomic percent) and Ta-C coatings against the diamond tip: (a) nanoindentation configuration, (b)-(d) sequence of nanoindentation simulations for a-C:H DLC coating and (e) scratch testing of a Ta-C DLC coating.

a)

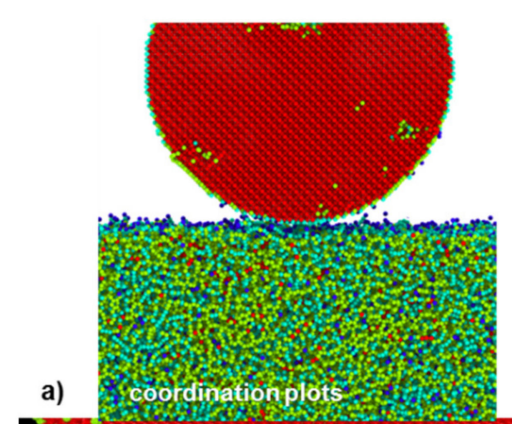

b)

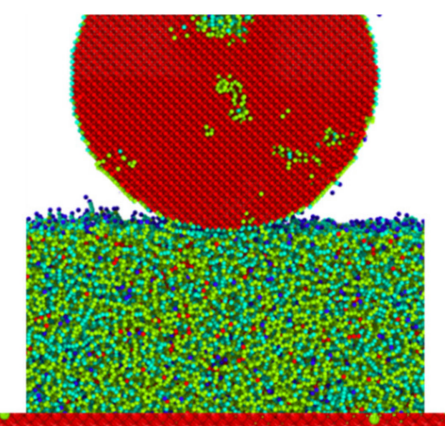

"normal" operation

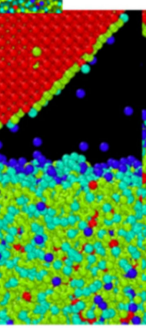

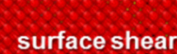

c)
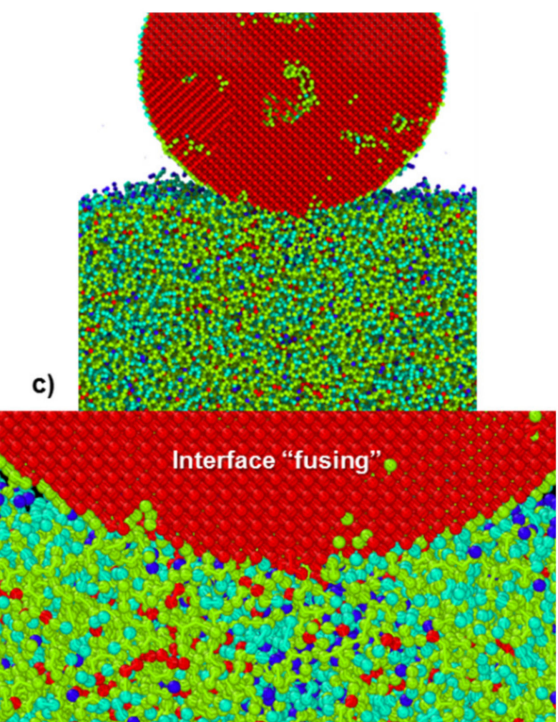

Figure 7. Different types of interactions with a diamond tip and ta-C DLC surface at different progressive loads: (a) initial surface sliding with near zero friction force, (b) surface graphitization and formation of shear layer and (c) surface chemistry and formation of covalent bonds associated with higher contact loads.

One of the long standing theories for friction behavior of DLC surfaces under contact is the surface stress state induced phase transformation to graphitization, which forms a low friction surface layer. This arises solely from the mechanical interaction between the 
two surfaces at ambient conditions, and although the ta- $C$ surface is more resistant than, for example, the lower density and smaller hybridization state a-C and a-C:H structures, the immediate surface is seen to exhibit a limited stage of glide associated with somewhat lower friction. However, the feature most prevalent in the ta- $C$ film is for increasing progressive loads its active tribochemistry, Figure 7c. Covalent bond formation is seen evidenced by differences in near surface coordination, the active tribochemistry foreseen to have implications with respect to behavior and integrity of the DLC system.

The results for the three principal different DLC films are collated to Figure 8 with respect to the frictional force in the different analysis cases, which is extracted directly from the scratch tip boundary conditions. The force is given as a function of step count, which relates to the output of results and is directly comparable to the applied progressive state of loading. Differing behavior is observed with respect to the evolution of frictional force during progressive loading. The lowest friction is obtained for the hydrogenated a-C:H system lubricated with multilayered graphene. In this case it is noted that the amorphous a$\mathrm{C}$ structure is supported by the graphene to result in a formation of a shear layer capable of supporting superlubricity-like conditions the longest with a very low coefficient of friction. Ultimately the interactions increase and triboreactivity takes place, but overall the frictional forces were consistently lowest. The a-C:H structure yields an average response with respect to the coefficient of friction. The state of superlubricity in this non-lubricated case persists only at the early stages of loading, after which friction increases and towards the end of the studied loading range also the covalent bond formation ensues. The difference between non-lubricated vs. lubricated to retain the state of superlubricity is obvious. The third case, the ta-C DLC film, has a differing response to sliding under non-lubricated conditions compared to a-C:H with and without lubrication. The ta- $\mathrm{C}$ film did not reach a low friction state of sliding at all, and during progressive loading tendency towards covalent bond formation and the greater density of higher degree of hybridization carbon structures results in a higher coefficient of friction.

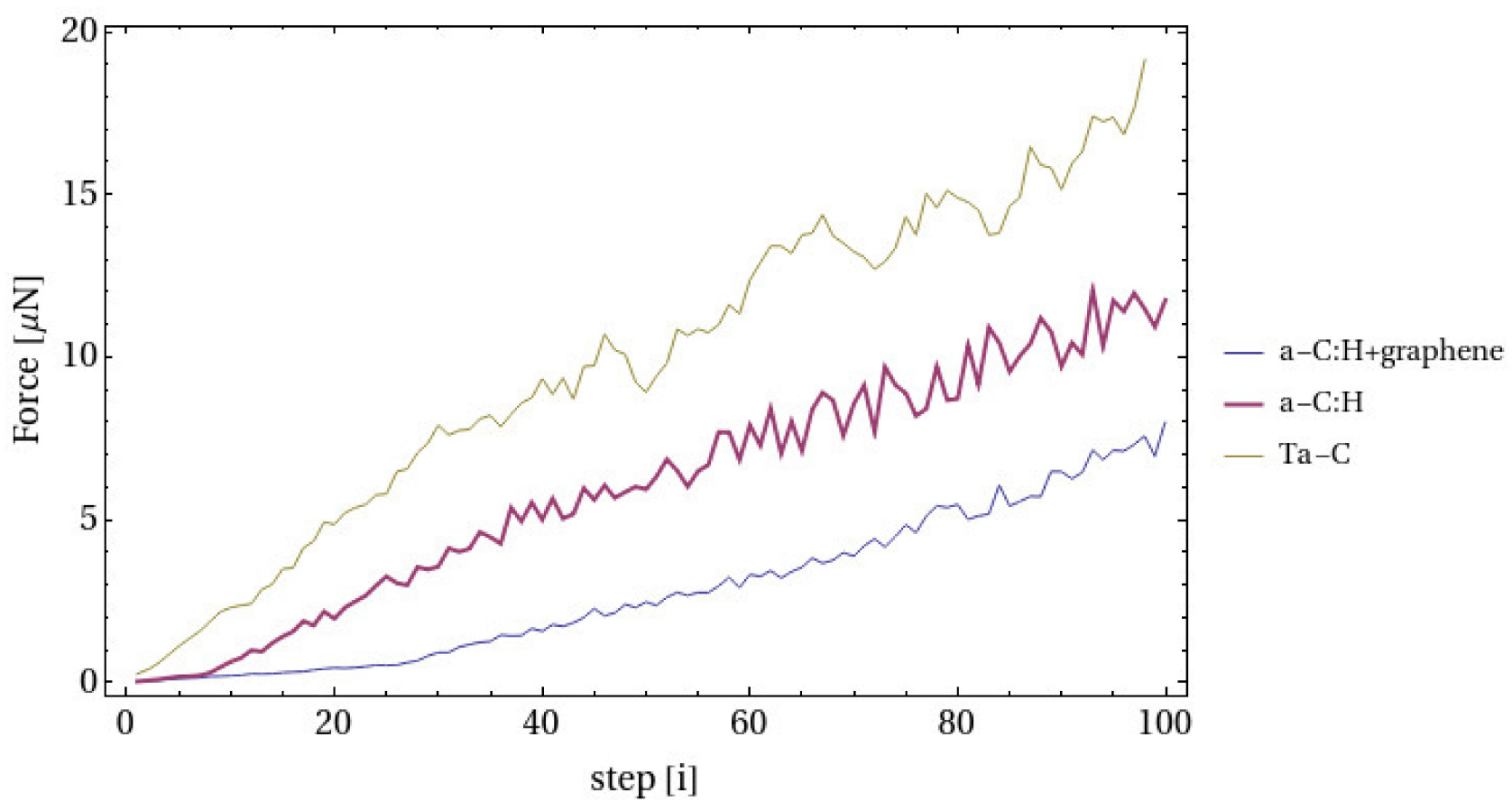

Figure 8. Nanoscratching of the different DLC surfaces and evolution of the friction force during progressive loading and sliding (given as a function of molecular dynamics (MD) model loading step comparable to the progressive loading and sliding).

With respect to upscaling of the friction results to the micromechanical analysis of the tribocontact we utilize the results followingly and select three principally differing analysis 
cases to study further using the microstructure containing models. First, the graphene lubricated a-C:H film with near superlubricity (coefficient of friction, $C O F=0.01$ ), second, the non-lubricated a-C:H film $(C O F=0.08)$ and third, the non-lubricated ta-C film $\left(m_{-} 0.2\right.$ and $\left.m \_0.6\right)$. These values cover the far ends of the studied DLC films with respect to tribochemical behavior.

\subsection{Microscale Contact, Micromechanics and DLC Film Fracture}

With respect to micromechanical modeling of the tribocontact, Figure 9 presents nominal 1st principal stresses before the nucleation of damage on DLC surfaces when the flat DLC block is sliding on the top of the surface in the groove direction (relative sliding angle $=0$, sliding in the direction of the surface grooves). Figure 9a presents the nominal state before the nucleation of any damage, Figure $9 b$ roughly at the time of damage initiation and Figure $9 \mathrm{c}$ a state where the coating has catastrophically failed. For an intact coating it can be seen that tensile stresses (red color contours) are formed at the valleys of surface texture, on some to the interfaces while on the top of the surface there are compressive stresses. At the stage of defect nucleation it is seen that the most probable locations for the coating failure are from the DLC coating surface, at the interface of the DLC to the bond layer and also at the bond layer to the substrate interface. In the case depicted in Figure 9 the coefficient of friction $m=0.2$, and it is seen that this leads to a scenario where both the surface roughness asperities ("peaks") and the interfaces between the DLC film and the bond layer, and the substrate, are showing signs of crack initiation and accumulation of damage. This behavior emphasizing both damage arising from surface topography and the different interfaces would appear to be a characteristic of cases where the coefficient of friction has a substantial value. As can be seen, to a degree, in Figure 9c, the ultimate failure in this model takes place both through the coating and at the substrate to the bond layer interface. The behavior of the different FE modeled micromechanical coating systems as a function of friction values representative of the MD results is presented in Figure 10. The first set of figures corresponded to conditions where damage initiation was taking place, the second where fracture of the coating had occurred. It can be seen that failure mechanism in a specific system were friction dependent, i.e., initiation of catastrophic failure takes place first within DLC, then at a bond layer and then at a bond layer to the substrate interface. The increased friction reduces the first principal tensile stresses on the top of the surface, rather promoting a mixed and more multiaxial state of stress. When friction coefficient was 0.6 high tensile stresses were formed on the top surface and those could be seen at lower stresses compared to contacts with lower friction coefficients. The increased friction influenced primarily the bond layer and its interface to the DLC film and the underlying substrate. This effect arose from plasticity, for example, the substrate to the bond layer interface exhibited increased plastic slip in the martensite like steel microstructure. This mismatch contributes adversely to the stress state driving brittle-like failure in the bond layer and DLC film, leading to increase in the initiation of damage and coating system scale failure. 


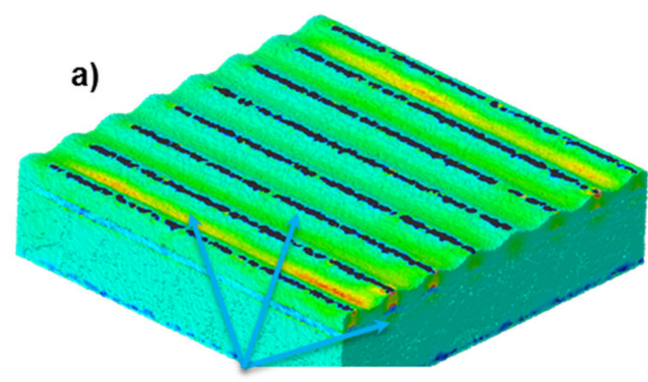

Surface grooving, microstructure, bond structures and contact influence behavior as is expected

b)

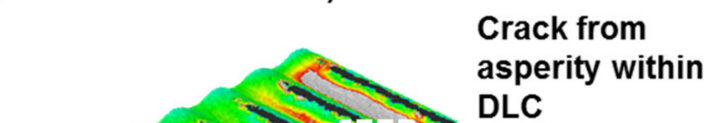

c)

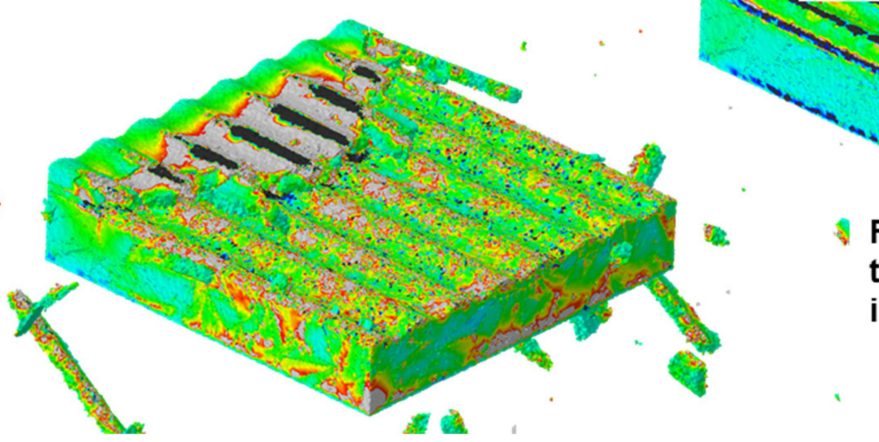

Figure 9. Evolution of 1st principal stress state at different stages of sliding and coating system damage accumulation: (a) sliding against flat DLC surface before nucleation of damage, (b) initiation of damage with multiple potential failure mechanisms and (c) final cracked and fully failed DLC coating.

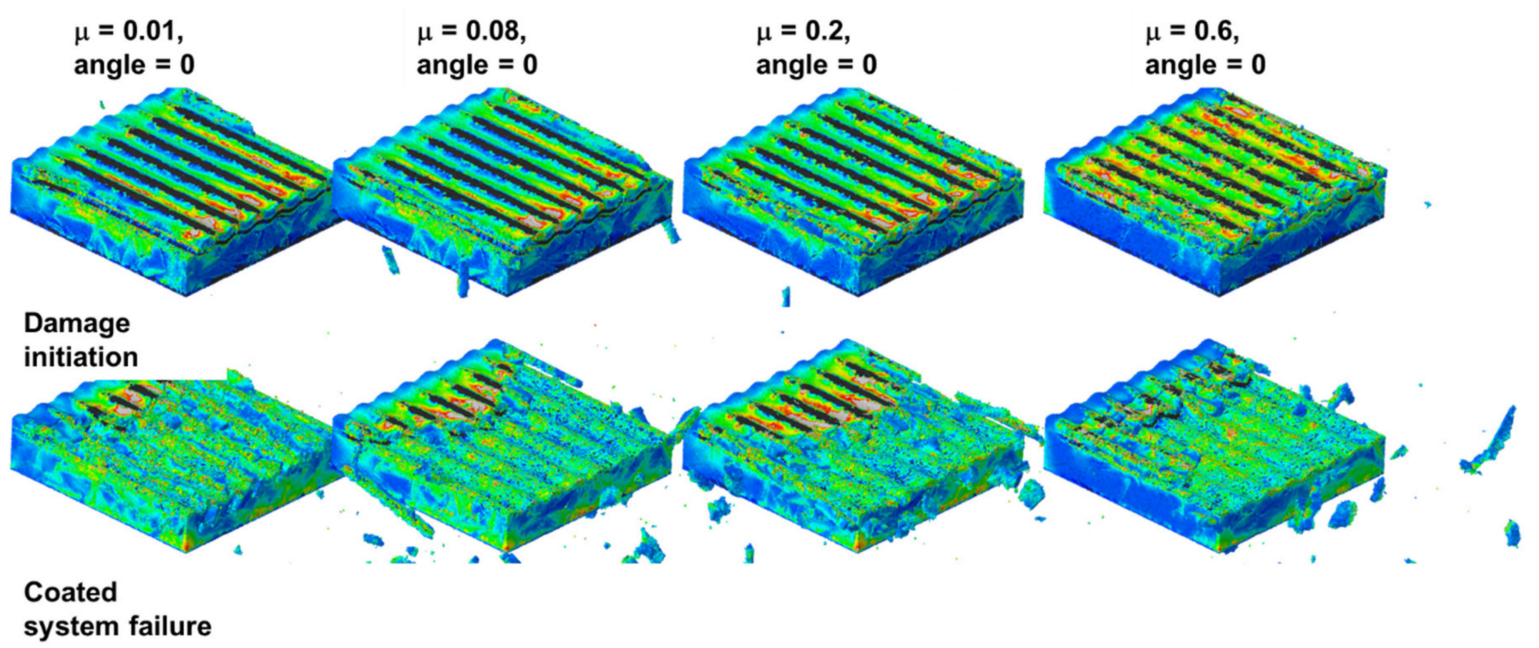

Figure 10. Fracture behavior of DLC with surface topography sliding against flat DLC: just before. Extensive crack initiation (top) and failed coating system (bottom).

The findings with respect to how damage accumulation and friction link to each other are further presented in Figure 11. In the figure damage in the different DLC coated systems was plotted as a function of sliding distance for the loading condition found to result in catastrophic failure of the coating. The damage variable was integrated such that coating damage $=\int_{V} D_{i}\left(x_{i}\right) d V$, where $D_{i}$ was the damage averaged over a specific finite element such that $\mathrm{D}=1$ if $\mathrm{D}>\mathrm{D}_{\mathrm{c}}$, where the critical damage parameter was $\mathrm{D}_{\mathrm{c}}=0.9$ and the element in question had lost $90 \%$ of its load carrying capacity (V being coating system volume). Thus, a value of "0.5" corresponded to a case where roughly half of the coating system (DLC, bond layer and interfaces) had exhibited failure beyond being able to contribute to carrying 
any of the applied stress resulting from the tribocontact. It is seen that there is a direct correlation between the coefficient of friction and the damage exhibited by the DLC coating system. For coefficients of friction of 0.01 and 0.08 , corresponding to either the a-C:H cases with or without graphene lubrication, the behavior differed significantly from the ones related to the ta- $\mathrm{C}$ films. The difference between the a-C:H and ta- $\mathrm{C}$ films could be also investigated by extracting a critical load from the simulation results (subplot in Figure 11), where the load Pc was determined to correspond to a situation where a first through coating system crack appears (through the coating or bond layer, or a crack resulting in loss of adhesion, essentially just a crack of the size of the characteristic dimensions of the micromechanical problem). The respective results indicate that the increase in friction was responsible for $30-40 \%$ loss in load carrying capacity of the DLC coated system. Differences with respect to the a-C:H films with or without lubricant operating near or at superlubricitylike conditions fall within $15 \%$. In this representation, as long as the load carrying capacity is retained, the best performance is obtained with the graphene lubricated a-C:H DLC film.

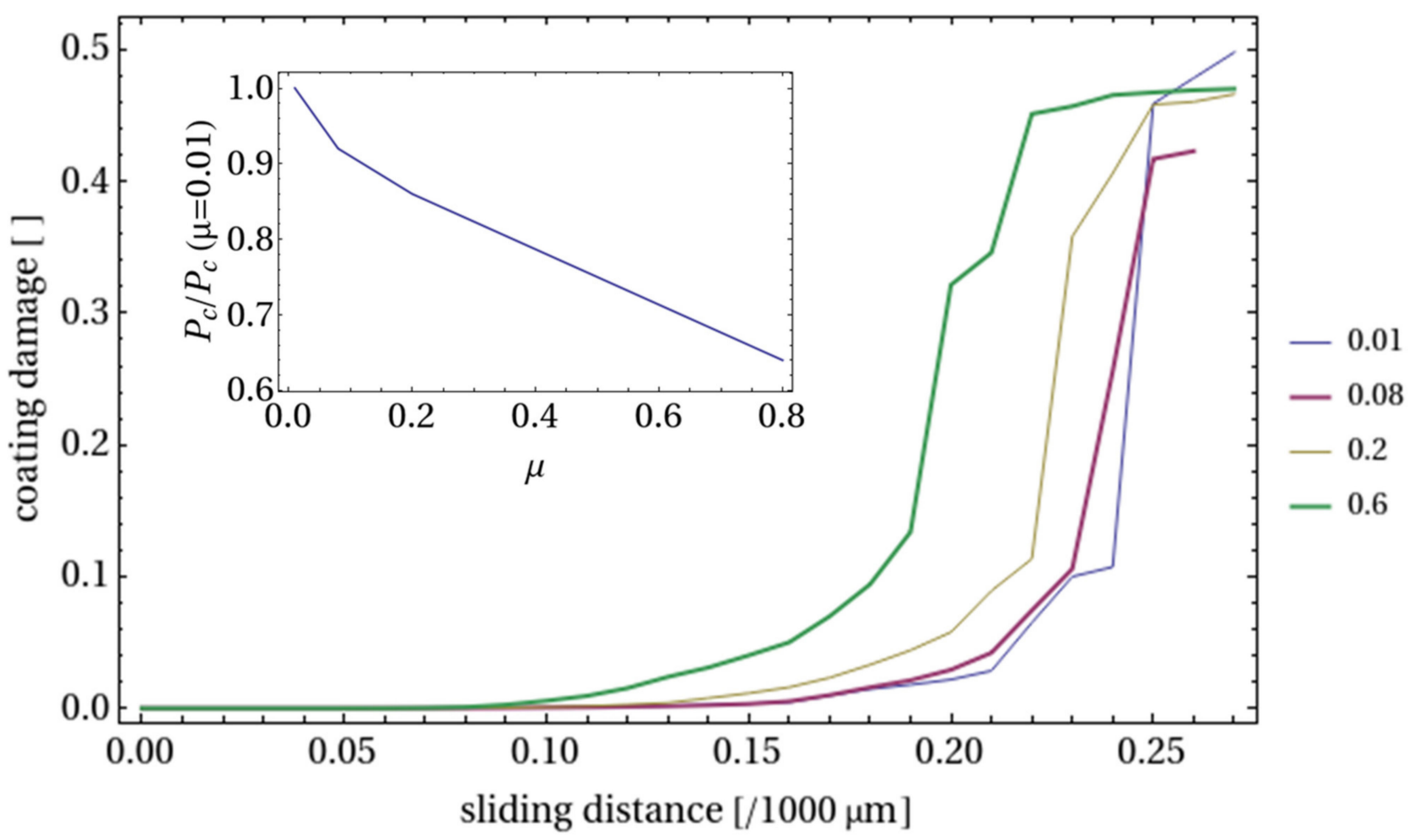

Figure 11. Sliding distance vs. DLC coating system damage for different coefficients of friction (embedded image: dependency of critical crack initiation load, Pc, on the coefficient of friction).

\section{Discussion}

As linking atomistic to continuum scale modeling is a non-trivial challenge even the linkage of something as straightforward as the coefficient of friction extracted from a lower scale model involving tribochemistry is not a common exercise. The methodology selected at the present work, performing the scale bridging by way of transferring data and essentially directly parameterizing a model at a higher scale, is the simplest that can be generally utilized. This leaves lot to be desired in terms of the concurrency of coupling and its depth, i.e., aspects such as the deformation or failure associated behaviors are not utilized directly in present work. This will necessitate longer term development efforts also in terms of computational methodologies, both in terms of quantitativeness of atomistic scale approaches, computational efficiency and challenges associated with differing temporal scales, and how to cast the problem with finite computational cost. Although results such 
as those in current work are promising, and enable one to investigate causalities in a fairly direct manner between the two principal scales, significant efforts and novel approaches going beyond the naive ways of performing scale bridging are a necessity.

To reach a friction coefficient below 0.01 is dependent on the atomistic structure $\left(\mathrm{sp}^{2} / \mathrm{sp}^{3}\right.$ ratio), 3D structure (ring structures vs. tetragonal regions), local density, shear induced structures and surface texture, degree of $\mathrm{H}$ passivation (in amorphous structure, surface termination) and tribochemical reactions (transfer layers, covalent bond formation and breakage during the tribological contact process). The process for developing low friction surfaces is highly dependent on a local atomistic stress-strain state (essentially applied load and loading conditions in general), i.e., greater stress-strain states can either damage favorable initial structures (for example, $\mathrm{H}$ passivation, $\mathrm{sp}^{2}$ hybridization, ring structures) or introduce friction-wise favorable hybridization states $\left(\mathrm{sp}^{2}\right.$ graphite and graphene layers). Since this response is dependent on the same factors as the low friction coefficient, the coating needs to be tailored at the nanoscale for a specific application to reach optimal tribologically favorable properties. An alternative is a fairly traditional frictional response and inability to exploit coating properties to begin with (e.g., adhesive fusing due to covalent bond formation and resulting thermal spiking). Lubrication reduces friction coefficient and changes the failure mechanism of the coating system. The tighter integration of DLC and lubricant design to obtain, and especially, retain, superlubricity-like conditions in application environments is an interesting direction of study where multiscale materials modeling efforts can drive the systematic investigation of how to establish the set conditions.

The contributions of current work are largely in methodology development. Although the work is based and relies on earlier experimental activities, especially the validation of the proposed approaches necessitates significant further efforts. Based on earlier results the results are reasonable, but directed and specific validation efforts are required. The complexities associated with modeling tribochemistry, deformation and failure processes and the roles of the numerous parameters in this regard necessitate joined experimental and modeling efforts to ensure and further develop the respective predictive capabilities. One topic is expanding the scope of scale bridging, which already due to the associated challenges is of a fundamental kind in terms of, for example, the respective deformation processes and how they can be reliably "mapped" from the atomistic to continuum scales. This is in any manner required to expand the "design space" that can be reliably investigated in search of innovative solutions and coatings, and also accelerates the pace of development by promoting the ease of parameterization across scales. Thus, adding to the modeling capabilities is required in driving further couplings across scales.

The future developments with respect to the present activity reside in the extension of its scope as presented earlier to better account for environmental conditions, also by way of introducing further coarse graining methods and means to address operational conditions and longer modeling timespans. The extension of the predictive scope and degree of validation to reach greater design spaces drives forward both the development of modeling methods and understanding of the tribological behavior of DLC films, and the overall design guidelines to that effect. A topic of interest in this regard is when the utilized means can be better utilized to discover alternative DLC compositions, doped films, etc., and tailor these in a targeted manner to specific functionality requirements.

\section{Summary and Conclusions}

This paper presented how failure mechanisms of DLC coatings at the scale of the microstructure can be linked with friction calculated via MD simulations and how to utilize the relationship to draw conclusions on this causal relation. In lubricated contacts the surface chemistry of DLC coatings changes leading to lower friction, as such reducing the stress and strain state in the micromechanical scale, resulting in better resistance against failure and greater coating load bearing capacity. The results of this work can be concluded as follows: 
- The utilized methodology linking MD modeling to micromechanical FE elements was found able to capture the effects of friction to coating failure behavior, producing a workflow where causal relations linking DLC tribochemistry to its mechanical endurance can be investigated quantitatively.

- The studied DLC films of a-C:H and ta-C type (a-C:H with and without graphene lubrication) yielded analysis results comparable to their expected tribochemistry, superlubricity-like conditions were best obtained with graphene lubricated a-C:H films for the greatest range of applied loading.

- The increased friction reduces the first principal tensile stresses on the top of the surface and rather influences the bond layer and its interface to the DLC film and the underlying substrate, thus reducing the lifetime of the coated system.

- The introduced modeling methodology will require and will be next validated over more complex conditions and in an effort to try to expand the degree of information that can be bridged from atomistic to microstructural scale modeling.

- The proposed methodology enables one to investigate the characteristics of DLC films, their tribochemistry and lubrication and bridge these results all the way to the product scale (microstructural scale) tribocontact and coating performance. The approach due to its simple scale bridging capabilities enables one to better investigate and design DLC films with an eye on application performance.

Author Contributions: Conceptualization, A.L. and K.H.; methodology, A.L and T.J.H.; software, A.L.; formal analysis, A.L. and T.J.H.; writing—original draft preparation, T.J.H. and A.L.; writingreview and editing, A.L. and T.J.H.; funding acquisition, K.H. All authors have read and agreed to the published version of the manuscript.

Funding: The authors acknowledge funding by the VTT Technical Research Centre of Finland Ltd.

Acknowledgments: The study was conducted as part of the Implementing Agreement (IA) on Advanced Materials for Transportation Applications (AMT), Annex IX Model based design of tribological coating systems. The Implementing agreement functions within a framework created by the International Energy Agency (IEA). The views, findings, and publications of the AMT IA do not necessarily represent the views or policies of the IEA or of all of its individual member countries.

Conflicts of Interest: The authors declare no conflict of interest.

\section{References}

1. Erdemir, A.; Donnet, C. Tribology of diamond-like carbon films: Recent progress and future prospects. J. Phys. D Appl. Phys. 2006, 39, R311-R327. [CrossRef]

2. Holmberg, K.; Matthews, A. (Eds.) Coatings Tribology: Properties Techniques and Applications in Surface Engineering; Tribol-ogy Series; Elsevier: Amsterdam, The Netherlands, 1994.

3. Holmberg, K.; Laukkanen, A.; Ronkainen, H.; Waudby, R.; Stachowiak, G.; Wolski, M.; Podsiadlo, P.; Gee, M.; Nunn, J.; Gachot, C.; et al. Topographical orientation effects on friction and wear in sliding DLC and steel contacts, part 1: Experimental. Wear 2015, 330-331, 3-22. [CrossRef]

4. Gao, G.T.; Mikulski, P.T.; Chateauneuf, A.G.M.; Harrison, J.A. The Effects of Film Structure and Surface Hydrogen on the Properties of Amorphous Carbon Films. J. Phys. Chem. B 2003, 107, 11082-11090. [CrossRef]

5. Holmberg, K.; Ronkainen, H.; Laukkanen, A.; Wallin, K. Friction and wear of coated surfaces - scales, modelling and simula-tion of tribomechanisms. Surf. Coat. Technol. 2007, 202, 1034-1049. [CrossRef]

6. Liu, Y.; Erdemir, A.; Meletis, E. An investigation of the relationship between graphitization and frictional behavior of DLC coatings. Surf. Coatings Technol. 1996, 86-87, 564-568. [CrossRef]

7. $\mathrm{Xu}, \mathrm{J} . ;$ Kawaguchi, M.; Kato, T. Evolution of transfer layers on steel balls sliding against hydrogenated amorphous carbon coatings in ambient air. Tribol. Int. 2014, 70, 42-51. [CrossRef]

8. Merkle, A.; Erdemir, A.; Eryilmaz, O.; Johnson, J.; Marks, L. In situ TEM studies of tribo-induced bonding modifications in near-frictionless carbon films. Carbon 2010, 48, 587-591. [CrossRef]

9. Haque, T.; Morina, A.; Neville, A.; Kapadia, R.; Arrowsmith, S. Non-ferrous coating/lubricant interactions in tribological con-tacts: Assessment of tribofilms. Tribol. Int. 2007, 40, 1603-1612. [CrossRef]

10. De Barros'Bouchet, M.; Martín, J.; Le-Mogne, T.; Vacher, B. Boundary lubrication mechanisms of carbon coatings by MoDTC and ZDDP additives. Tribol. Int. 2005, 38, 257-264. [CrossRef] 
11. Kano, M. Super low friction of DLC applied to engine cam follower lubricated with ester-containing oil. Tribol. Int. 2006, 39, 1682-1685. [CrossRef]

12. Vercammen, K.; Van Acker, K.; Vanhulsel, A.; Barriga, J.; Arnšek, A.; Kalin, M.; Meneve, J. Tribological behaviour of DLC coatings in combination with biodegradable lubricants. Tribol. Int. 2004, 37, 983-989. [CrossRef]

13. Vengudusamy, B.; Green, J.H.; Lamb, G.D.; Spikes, H.A. Behaviour of MoDTC in DLC/DLC and DLC/steel contacts. Tribol. Int. 2012, 54, 68-76. [CrossRef]

14. Abdullah Tasdemir, H.; Wakayama, M.; Tokoroyama, T.; Kousaka, H.; Umehara, N.; Mabuchi, Y.; Higuchi, T. Ultra-lowfriction of tetrahedral amorphous diamond-like carbon (ta-C DLC) under boundary lubrication in poly alpha-olefin (PAO) with additives. Tribol. Int. 2013, 65, 286-294. [CrossRef]

15. Kržan, B.; Novotny-Farkas, F.; Vizintin, J. Tribological behavior of tungsten-doped DLC coating under oil lubrication. Tribol. Int. 2009, 42, 229-235. [CrossRef]

16. Masuko, M.; Ono, T.; Aoki, S.; Suzuki, A.; Ito, H. Friction and wear characteristics of DLC coatings with different hydrogen content lubricated with several Mo-containing compounds and their related compounds. Tribol. Int. 2015, 82, 350-357. [CrossRef]

17. Kogovšek, J.; Kalin, M. Lubrication performance of graphene-containing oil on steel and DLC-coated surfaces. Tribol. Int. 2019, 138, 59-67. [CrossRef]

18. Wang, S.; Wu, T.; Wu, H.; Kwok, N. ModelingWear State Evolution Using Real-TimeWear Debris Features. Tribol. Tran. 2017, 60, 1022-1032. [CrossRef]

19. Simonovic, K.; Kalin, M. Methodology of a statistical and DOE approach to the prediction of performance in tribology - A DLC boundary-lubrication case study. Tribol. Int. 2016, 101, 10-24. [CrossRef]

20. Pagnoux, G.; Fouvry, S.; Peigney, M.; Delattre, B.; Mermaz-Rollet, G. A model for single asperity perturbation on lubricated sliding contact with DLC-coated solids. Tribol. Int. 2015, 82, 423-430. [CrossRef]

21. Laukkanen, A.; Holmberg, K.; Ronkainen, H.; Stachowiak, G.; Podsiadlo, P.; Wolski, M.; Gee, M.; Gachot, C.; Li, L. Topo-graphical orientation effects on surface stresses influencing on wear in sliding DLC contacts, Part 2: Modelling and simulations. Wear 2017, 388-389, 18-28. [CrossRef]

22. Hakala, T.J.; Laukkanen, A.; Suhonen, T.; Holmberg, K. A finite-element model for a paste lubricated steel wire vs cast iron contact. Tribol. Int. 2020, 150, 106362. [CrossRef]

23. Zhang, Y.; Lu, L.; Gong, Y.; Zhang, J.; Zeng, D. Finite Element Modeling and Experimental Validation of Fretting Wear Scars in a Press-Fitted Shaft with an Open Zone. Tribol. Trans. 2018, 61, 585-595. [CrossRef]

24. AlMotasem, A.; Posselt, M.; Bergström, J. Nanoindentation and nanoscratching of a ferrite/austenite iron bi-crystal: An atom-istic study. Tribol. Int. 2018, 127, 231-239. [CrossRef]

25. Chen, H.; Zhang, G.; Lu, Z.; Bai, L. Frictional behaviors of diamond-like carbon films under water lubrication: A molecular dynamics study. Tribol. Int. 2021, 153, 106609. [CrossRef]

26. Lan, H.; Kato, T.; Liu, C. Molecular dynamics simulations of atomic-scale tribology between amorphous DLC and Si-DLC films. Tribol. Int. 2011, 44, 1329-1332. [CrossRef]

27. Song, J.; Zhao, G. A molecular dynamics study on water lubrication of PTFE sliding against copper. Tribol. Int. 2019, 136, 234-239. [CrossRef]

28. Bai, L.; Srikanth, N.; Zhao, B.; Liu, B.; Liu, Z.; Zhou, K. Lubrication mechanisms of graphene for DLC films scratched by a di-amond tip. J. Phys. D Appl. Phys. 2016, 49, 485302. [CrossRef]

29. Ryan, K.E.; Keating, P.L.; Jacobs, T.D.B.; Grierson, D.S.; Turner, K.T.; Carpick, R.W.; Harrison, J.A. Simulated Adhesion be-tween Realistic Hydrocarbon Materials: Effects of Composition, Roughness, and Contact Point. Langmuir 2014, 30, 2028-2037. [CrossRef] [PubMed]

30. Holmberg, K.; Laukkanen, A.; Hakala, T.; Ronkainen, H.; Suhonen, T.; Wolski, M.; Posiadlo, P.; Stachowiak, G.; Gachot, C.; Li, L. Topography orientation effects on friction and wear in sliding DLC and steel contacts, part 3: Experiments under dry and lu-bricated conditions. Wear 2021. submitted.

31. Wolski, M.; Podsiadlo, P.; Stachowiak, G.; Holmberg, K.; Laukkanen, A.; Ronkainen, H.; Gee, M.; Nunn, J.; Gachot, C.; Li, L. Multiscale characterisation of 3D surface topography of DLC coated and uncoated surfaces by directional blanket covering (DBC) method. Wear 2017, 388-389, 47-56. [CrossRef]

32. Stuart, S.J.; Tutein, A.B.; Harrison, J.A. A reactive potential for hydrocarbons with intermolecular interactions. J. Chem. Phys. 2000, 112, 6472-6486. [CrossRef]

33. Harrison, J.; White, C.; Colton, R.; Brenner, D. Nanoscale investigation of indentation, adhesion and fracture of diamond (111) surfaces. Surf. Sci. 1992, 271, 57-67. [CrossRef]

34. Harrison, J.A.; White, C.T.; Colton, R.J.; Brenner, D.W. Investigation of the atomic-scale friction and energy dissipation in diamond using molecular dynamics. Thin Solid Films 1995, 260, 205-211. [CrossRef]

35. Harrison, J.A.; Perry, S.S. Friction in the Presence of Molecular Lubricants and Solid/Hard Coatings. MRS Bull. 1998, 23, 27-31. [CrossRef]

36. Plimpton, S. Fast Parallel Algorithms for Short-Range Molecular Dynamics. J. Comput. Phys. 1995, 117, 1-19. [CrossRef]

37. Ranganathan, R.; Rokkam, S.; Desai, T.; Keblinski, P. Generation of amorphous carbon models using liquid quench method: A reactive molecular dynamics study. Carbon 2017, 113, 87-99. [CrossRef] 
38. Laukkanen, A.; Pinomaa, T.; Holmberg, K.; Andersson, T. Effective interface model for design and tailoring of WC-Co microstructures. Powder Metall. 2016, 59, 20-30. [CrossRef]

39. Lindroos, M.; Cailletaud, G.; Laukkanen, A.; Kuokkala, V.T. Crystal plasticity modeling and characterization of the defor-mation twinning and strain hardening in Hadfield steels. Mater. Sci. Eng. A 2018, 720, 145-159. [CrossRef]

40. Wallin, K.; Laukkanen, A. Aspects of cleavage fracture initiation - relative influence of stress and strain. Fatigue Fract. Eng. Mater Struct. 2006, 29, 788-798. [CrossRef]

41. Holmberg, K.; Laukkanen, A.; Turunen, E.; Laitinen, T. Wear resistance optimisation of composite coatings by computational microstructural modelling. Surf. Coatings Technol. 2014, 247, 1-13. [CrossRef]

42. Holmberg, K.; Laukkanen, A.; Ghabchi, A.; Rombouts, M.; Turunen, E.; Waudby, R.; Suhonen, T.; Valtonen, K.; Sarlin, E. Computationalmodelling based wear resistance analysis of thick composite coatings. Tribol. Int. 2014, 72, 13-30. [CrossRef]

43. Laukkanen, A.; Holmberg, K.; Ronkainen, H.; Wallin, K. Cohesive Zone Modeling of Initiation and Propaga-tion of Multiple Cracks in Hard Thin Surface Coatings. Fatig. Fract. Mech. 2011, 37, 646-674. 